\title{
Robôs Humanoides na Educação: Um Mapeamento Sistemático com Base na Produção Científica Nacional e Internacional
}

\author{
Humanoid Robots in Education: A Systematic \\ Mapping Based on National and International \\ Scientific Production
}

\author{
Edvanilson Santos de Oliveira \\ Universidade Federal do Mato Grosso do Sul \\ Patrícia Sândalo Pereira \\ Universidade Federal do Mato Grosso do Sul
}

\begin{abstract}
Resumo: O presente artigo teve como objetivo investigar como se dá o uso de robôs humanoides na educação em âmbito nacional e internacional. Para tanto, realizamos um Mapeamento Sistemático da Literatura (MSL) a partir de teses, dissertações e artigos científicos publicados no período compreendido entre os anos de 2009 e 2018. Especificou-se os tipos de robôs, aspectos metodológicos, didáticos e curriculares. Organizamos as análises dos dados em quatro categorias: Linguagem, Códigos e suas Tecnologias, Ciências da Natureza, Matemáticas e suas Tecnologias, Ciências Humanas e suas Tecnologias e Competências e habilidades sociais, culturais, afetivas e psicomotoras. O resultado desta pesquisa produz fundamentação teórica no domínio das novas tecnologias educacionais, revelando a necessidade de estudos sobre as interações humano-robô e os impactos do uso de robôs humanoides na educação.
\end{abstract}

Palavras-chave: Robôs Humanoides, Educação, Mapeamento Sistemático.

\begin{abstract}
This article aimed to investigate how humanoid robots are used in education at national and international levels. For that, we carried out a Systematic Mapping of Literature (MSL) from theses, dissertations and scientific articles published in the period between the years 2009 and 2018. The types of robots, methodological, didactic and curricular aspects were specified. We organize data analysis in four categories: Language, Codes and their Technologies, Natural Sciences, Mathematics and their Technologies, Human Sciences and their Technologies and Social, cultural, affective and psychomotor skills. The result of this research produces theoretical foundation in the domain of new educational technologies, revealing the need for studies on human-robot interactions and the impacts of the use of humanoid robots on education.
\end{abstract}

Keywords: Humanoid Robots, Education, Systematic Mapping.

OLIVEIRA, Edvanilson Santos de; PEREIRA, Patrícia Sândalo. Robôs Humanoides na Educação: Um Mapeamento Sistemático com Base'na Produção Cientifica Nacional e Internacional. Informática na Educação: teoria \& prática, Porto Alegre, v. 23, n. 3 , p. 27-47, set./dez. 2020. 


\section{Introdução}

A compreensão das novas formas de ensinar e aprender pode tornar a sala de aula um ambiente agradável, desafiador e rico para a construção do conhecimento por meio de tecnologias intelectuais.

A popularização dos computadores e o seu uso em contextos educacionais, introduzidos por Seymour Papert na década de 1980 no Laboratório de Inteligência Artificial do Massachusetts Institute of Technology (MIT), possibilitaram a introdução de conceitos de programação e robótica na escola. Neste contexto, com os constantes avanços no âmbito da Ciência e Tecnologia, é possível perceber mudanças socioculturais na sociedade contemporânea, nas diversas áreas do conhecimento.

Ao pensarmos no uso da robótica como recurso tecnológico na educação, consideramos o fato de que ela também está presente em diversos países (MIRANDA et al., 2012). Assim, verificamos o andamento dos estudos e pesquisas relacionadas à presente temática no Brasil e no Exterior, tendo em vista que o Mapeamento Sistemático da Literatura assume um papel preponderante para uma investigação que tenha como proposta contribuir para o enriquecimento do presente campo de estudo (RUMRILL; FITZGERALD, 2001).

A Robótica Educacional (RE) ou Robótica Pedagógica (RP) pode ser definida como "a utilização da robótica industrial num contexto onde as atividades de construção e controle de dispositivos, usando kits de montar ou outros materiais, propicia o manuseio conceitual em ambiente de aprendizagem" (BARNAUSKAS et al., 1999, p. 64). Entretanto, é importante enfatizar que a proposta do uso de robôs humanoides não se baseia na utilização de kits de montagens, mas na aplicação de robôs montados industrialmente com aparência do corpo humano e, no presente estudo, utilizados para fins educacionais.

Neste sentido, buscamos investigar como se dá o uso de robôs humanoides na educação no âmbito nacional e internacional, refletindo sobre os aspectos metodológicos, didáticos e curriculares presentes nas práticas educativas pautadas na aplicação de artefatos tecnológicos. Nossos objetivos específicos foram: 1) Realizar o Mapeamento Sistemático da Literatura das pesquisas realizadas por pesquisadores nacionais e internacionais; 2) Discutir as características relevantes inerentes ao uso de robôs humanoides no contexto educacional; 3) Refletir sobre os aspectos metodológicos, didáticos e curriculares presentes nas práticas educativas analisadas. Para tanto, utilizamos as etapas de Mapeamento Sistemático de Literatura de acordo com Law \& Philp (2002) e Magee (1998). O estudo pretende responder ao seguinte questionamento: De que maneira se dá o uso de robôs humanoides com fins educacionais, dentro do contexto nacional e internacional?

Nessa perspectiva, entendemos que o uso de robôs humanoides pode ser empregado no âmbito educacional, apesar de constituir uma tecnologia ainda emergente no panorama nacional, partimos da premissa de que esse tipo de tecnologia aliado a uma proposta didática/metodológica adequada pode vir a configurar-se como um instrumento pedagógico capaz de potencializar o 
desenvolvimento cognitivo, além de tornar o ambiente escolar um lugar desafiador, dinâmico e divertido, aspectos essenciais para a produção de saberes, competências e habilidades.

Para alcançar os objetivos do presente estudo, trazemos, na seção 2 (dois), uma discussão sobre os aspectos históricos e conceituais dos robôs humanoides. Em seguida, na seção 3 (três) descrevemos a metodologia do estudo. Na seção 4 (quatro), abordamos os resultados obtidos, bem como a análise e discussão. Finalmente, na seção 5 (cinco) apresentamos nossas considerações finais.

\section{Robôs Humanoides: Aspectos Históricos e Conceituais}

A ficção científica liderou o campo da robótica, como tantas outras disciplinas, com visões de tecnologia muito além do estado da arte vivido na contemporaneidade, contudo, é importante compreendermos, inicialmente, de maneira ampla, os aspectos históricos relacionados ao uso de robôs.

Desde a antiguidade, o homem tem construído autômatos e figuras animadas artificialmente. Os artefatos mecânicos mais antigos, capazes de gerar seu auto funcionamento, baseiam-se em técnicas de transporte da água. É o caso do relógio egípcio clepsidra (OLIVEIRA, 2015).

Com o passar dos anos, os artefatos construídos também ganham espaço no teatro. É o caso da peça R. U. R (Rossum's Universal Robots), criada pelo escritor tcheco Harel Capek e encenada em Praga em 1921, produção teatral nova-iorquina data de 1922. No referido trabalho, Capek introduziu, pela primeira vez, a expressão robô, que denota a um mecanismo automático, em geral, com aspecto semelhante ao de um homem. "Do tcheco robota, robô significa trabalho forçado, ou escravo. Robotnik, também do tcheco, é a palavra para servo ou escravo" (REGIS, 2012, p. 71).

Nesse contexto, os robôs eram interpretados por atores humanos e lidavam com questões de escravidão e subjugação que eram metáforas para as preocupações dos trabalhadores humanos da época. Esses primeiros robôs também foram os primeiros humanoides, pelo menos no teatro. Os robôs ganharam outra posição na ficção científica com os trabalhos de Asimov, em que o termo "robótica" foi definido em 1941 como uma disciplina de estudo. Neste sentido, mais uma vez, a forma e as funções dos robôs estudados e construídos (na ficção) eram humanoides. A Figura 1 (um) mostra a evolução da ficção científica desde os primeiros trabalhos até as representações em filmes na modernidade. 
Figura 1 - Evolução de trabalhos com uso de robôs no teatro e na ficção científica (1921-2018)

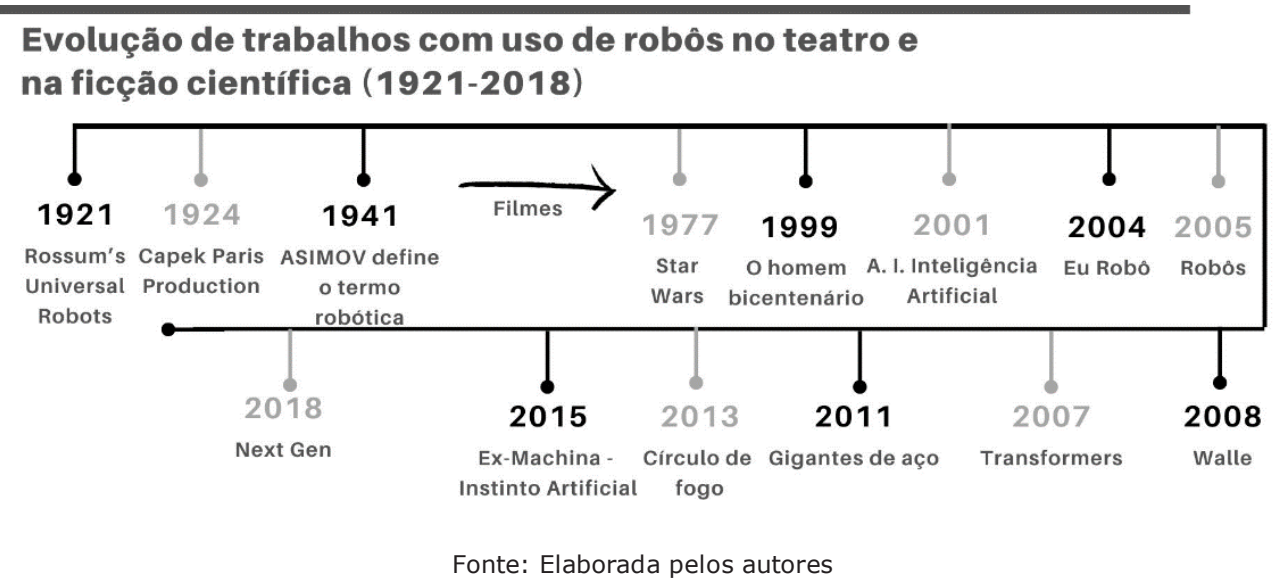

A definição do humanoide, enquanto superficialmente na forma, poderia ser ancorada pela função exercida pelos robôs. Habilidades para rolar ou lutar com múltiplos membros são melhorias que fazem esses robôs fictícios executarem, com habilidade, ações humanas. Contudo, uma máquina que executa tarefas repetitivas e de alta velocidade de uma maneira completamente não antropomórfica, como uma prensa de impressão, não é considerada humanoide.

Portanto, há uma certa tensão na definição do robô humanoide, principalmente com base na tentativa de equilibrar forma e função.

Para o presente estudo: "Os humanoides são máquinas que têm a forma ou a função dos humanos" (BEKEY et al., 2008, p. 71). Os casos em que máquinas têm forma e função humanas são raros hoje em dia, apesar da forte especulação da ficção científica sinalizar que isso poderá mudar no futuro.

Sendo assim, após abordarmos os aspectos históricos e conceituais dos robôs humanoides, apresentamos, na próxima seção, os aspectos metodológicos da pesquisa.

\section{Metodologia}

A pesquisa com base no Mapeamento Sistemático de Literatura (MSL) é, em geral, fundamentada em estudos anteriores, com essência qualitativa dos dados obtidos nas leituras, de modo a contribuir com o aprofundamento de um determinado campo científico ou até mesmo analisar metodologicamente estudos anteriores (RUMRILL; FITZGERALD, 2001).

A seguir, descrevemos, de modo geral, as etapas do MSL: 
Figura 2 - Descrição das etapas do processo de MSL

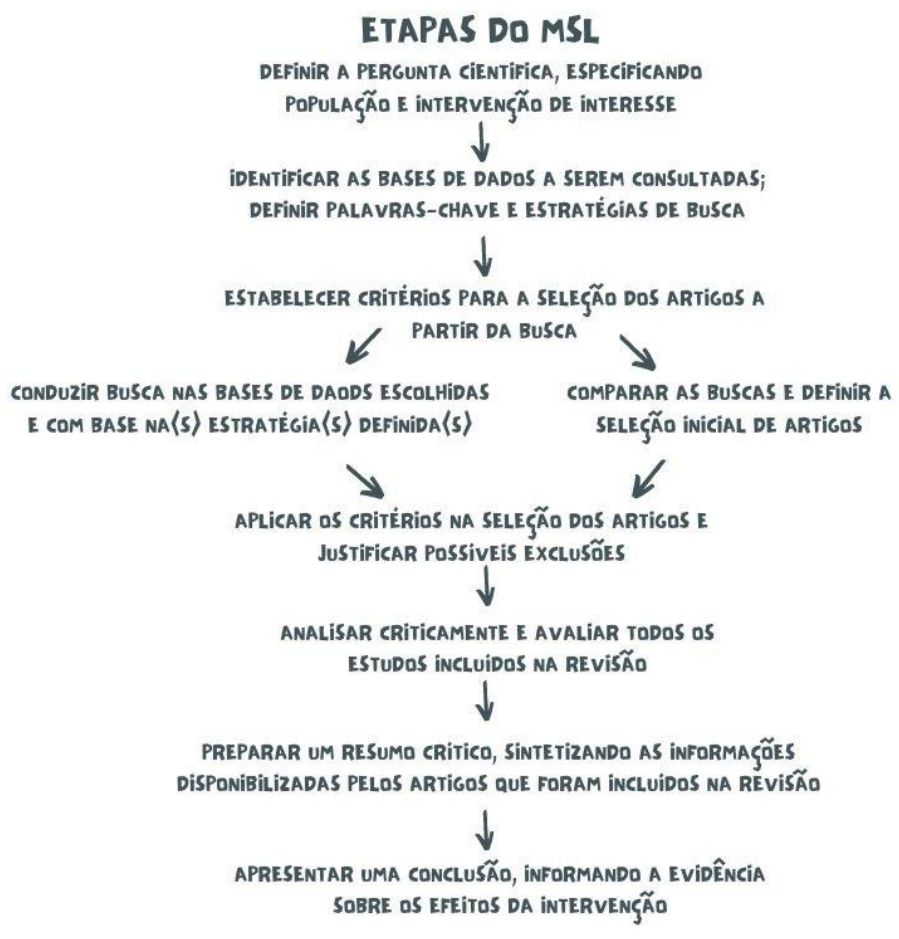

Fonte: Elaborada pelos autores, adaptado de Law \& Philp (2002) e Magee (1998)

Uma String de busca corresponde à combinação dos conceitos-chave e, para realização de busca dos dados iniciais da pesquisa, utilizamos termos em língua portuguesa e inglesa nas consultas aos bancos de dados: robôs humanoides usados na educação (humanoid robots used in the education), robôs humanoides na educação (humanoid robots in education) e robôs humanoides e aprendizagem (humanoid robots and learning). Visando obter de forma mais efetiva a aquisição e retorno dos dados, usamos o operador lógico "AND", representando uma conjunção. Quanto aos locais de busca, no âmbito nacional, foi a Biblioteca Digital Brasileira de Teses e Dissertações (BDTD) ${ }^{1}$, por ser uma base de dados aberta, com as pesquisas de mestrado e doutorado, tendo o português como língua oficial. No contexto internacional, IEEE Xplore Digital Library $^{2}$, Education Resources information Center (ERIC) ${ }^{3}$, por ser uma base de dados com foco em pesquisas e informações educacionais e que incluem dissertações e teses de âmbito internacional, tendo o inglês como língua oficial.

Selecionamos artigos completos, dissertações e teses que abordassem as questões de pesquisa publicadas entre 2009 a 2018, em seguida, utilizamos, como critério de inclusão para leitura e análise, as pesquisas que apresentem foco na utilização dos robôs humanoides em processos educacionais. A Tabela 1 (um) mostra as bases de dados e strings de busca utilizadas:

\footnotetext{
${ }^{1} \mathrm{http} / / /$ bdtd.ibict.br/vufind/

${ }^{2} \mathrm{http}: / /$ ieeexplore.ieee.org/Xplore/home.jsp

${ }^{3}$ https://eric.ed.gov
} 
Tabela 1 - Base de dados e protocolos de pesquisa

\begin{tabular}{|l|l|}
\hline \multicolumn{1}{|c|}{ Base de Dados } & \multicolumn{1}{c|}{ Protocolos de Pesquisa } \\
\hline $\begin{array}{l}\text { Biblioteca Digital Brasileira de Teses e Dissertações- } \\
\text { BDTD }\end{array}$ & $\begin{array}{l}\text { Robôs humanoides na educação, Titulo, Todos os } \\
\text { Termos, desde } 2009\end{array}$ \\
\hline IEEE Explore & $\begin{array}{l}\text { (((humanoids robots in the education) AND } \\
\text { humanoids robots used in the education }) \text { AND } \\
\text { humanoids robots ad learning }) \text { under advanced } \\
\text { search options, }<\text { Publication Year: 2009-2018>, } \\
\text { Full Text and Metadata }>\end{array}$ \\
\hline ERIC & $\begin{array}{l}\text { Humanoid robots in education and humanoid robots } \\
\text { used in the education, desde 2009. }\end{array}$ \\
\hline
\end{tabular}

Fonte: Elaborada pelos autores

Os trabalhos duplicados encontrados em outras fontes, estudos secundários, documentos que não apresentaram versões completas para leitura e estudos que não abordavam a questão de pesquisa, foram excluídos das análises futuras.

\section{Resultados e Discussões}

Nesta seção, são apresentados os resultados obtidos no processo de MSL realizado, bem como a análise dos trabalhos selecionados, os quais apresentam estudos relacionados ao uso de robôs humanoides no contexto educacional.

\subsection{Informações gerais dos trabalhos primários}

O processo de busca retornou um total de 66 (sessenta e seis) trabalhos, extraindo-se, neste caso, os dados gerais por portal de busca: título, autores, abordagem de pesquisa, local de pesquisa, ano publicação, país de origem dos pesquisadores. O processo de recolha dos dados consistiu na filtragem dos trabalhos potencialmente relevantes. Após essa etapa, realizamos a análise dos estudos incluídos, considerados relevantes do ponto de vista da contribuição da pesquisa com a questão norteadora do presente estudo, compreendendo um total de 26 (vinte e seis) artigos científicos. Em seguida, prosseguimos com a leitura completa do conteúdo dos trabalhos, procurando as informações relevantes.

A Tabela 2 (dois) apresenta, de forma sucinta, o processo de evolução da recolha dos dados. $\mathrm{Na}$ coluna à esquerda, encontram-se dispostos os portais de busca utilizados. A coluna seguinte apresenta a quantidade de artigos retornados na primeira etapa do mapeamento sistemático, por meio das strings de busca. Nas demais seções, estão os resultados da primeira seleção, com os trabalhos potencialmente relevantes, e da segunda seleção, com o quantitativo de trabalhos excluídos, compreendidos nos trabalhos duplicados, irrelevantes e indisponíveis, em adição aos trabalhos primários, considerados por apresentar contribuições significativas para área. 
Tabela 2 - Base de dados e protocolos de pesquisa

\begin{tabular}{|c|c|c|c|c|c|c|}
\hline \multicolumn{7}{|c|}{ Seleção de Trabalhos primários } \\
\hline \multirow[t]{3}{*}{ Portais } & \multirow{3}{*}{$\begin{array}{l}\text { Trabalhos } \\
\text { retomados }\end{array}$} & $1^{\text {a }}$ Seleção & \multicolumn{4}{|c|}{$2^{a}$ Seleção } \\
\hline & & $\begin{array}{l}\text { Potencialmente } \\
\text { relevantes }\end{array}$ & \multicolumn{3}{|c|}{ Excluídos } & Incluídos \\
\hline & & & 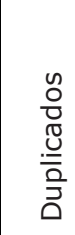 & 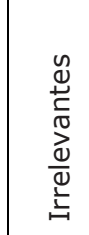 & 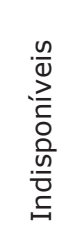 & $\begin{array}{l}\text { Trabalhos } \\
\text { primários }\end{array}$ \\
\hline $\begin{array}{l}\text { Biblioteca } \\
\text { Digital } \\
\text { Brasileira de } \\
\text { Teses e } \\
\text { Dissertações- } \\
\text { BDTD }\end{array}$ & 1 & 1 & 0 & 0 & 0 & 1 \\
\hline ERIC & 17 & 10 & 0 & 7 & 0 & 10 \\
\hline IEEE Xplorer & 48 & 15 & 0 & 31 & 2 & 15 \\
\hline Total & 66 & 26 & 0 & 38 & 2 & 26 \\
\hline
\end{tabular}

Fonte: Elaborada pelos autores

Verificamos que, dos trabalhos retornados, o portal IEEE Xplorer foi o que apresentou número mais expressivo, compreendido em 48 (quarenta e oito) artigos, seguido do portal ERIC com 17 (dezessete) trabalhos e, como menor quantidade, a Biblioteca de Teses e Dissertações, apresentando uma dissertação.

Nossa primeira etapa de seleção, buscou os trabalhos relevantes, por meio de leitura e análise dos títulos e resumos das publicações retornadas. Essa etapa consistiu em identificar as aplicações dos robôs humanoides com fins educacionais.

Em uma segunda etapa, identificamos os trabalhos excluídos e incluídos, realizando para tanto a leitura e análise do resumo, da introdução e da conclusão dos trabalhos obtidos na etapa anterior. A partir dessa segunda etapa, foi verificado 0 (zero) trabalhos duplicados, 7 (sete) trabalhos irrelevantes no ERIC, 30 (trinta) no portal IEEE Xplorer e 2 (dois) trabalhos indisponíveis.

Os trabalhos selecionados para análise, considerados como trabalhos primários, foram 1 (um) na BDTD, 10 (dez) no portal ERIC e 15 (quinze) trabalhos no portal IEEE Xplorer.

A Figura 3 (três) apresenta a distribuição temporal das publicações com o respectivo quantitativo por ano. 
Figura 3 - Distribuição temporal das publicações com o respectivo quantitativo por ano

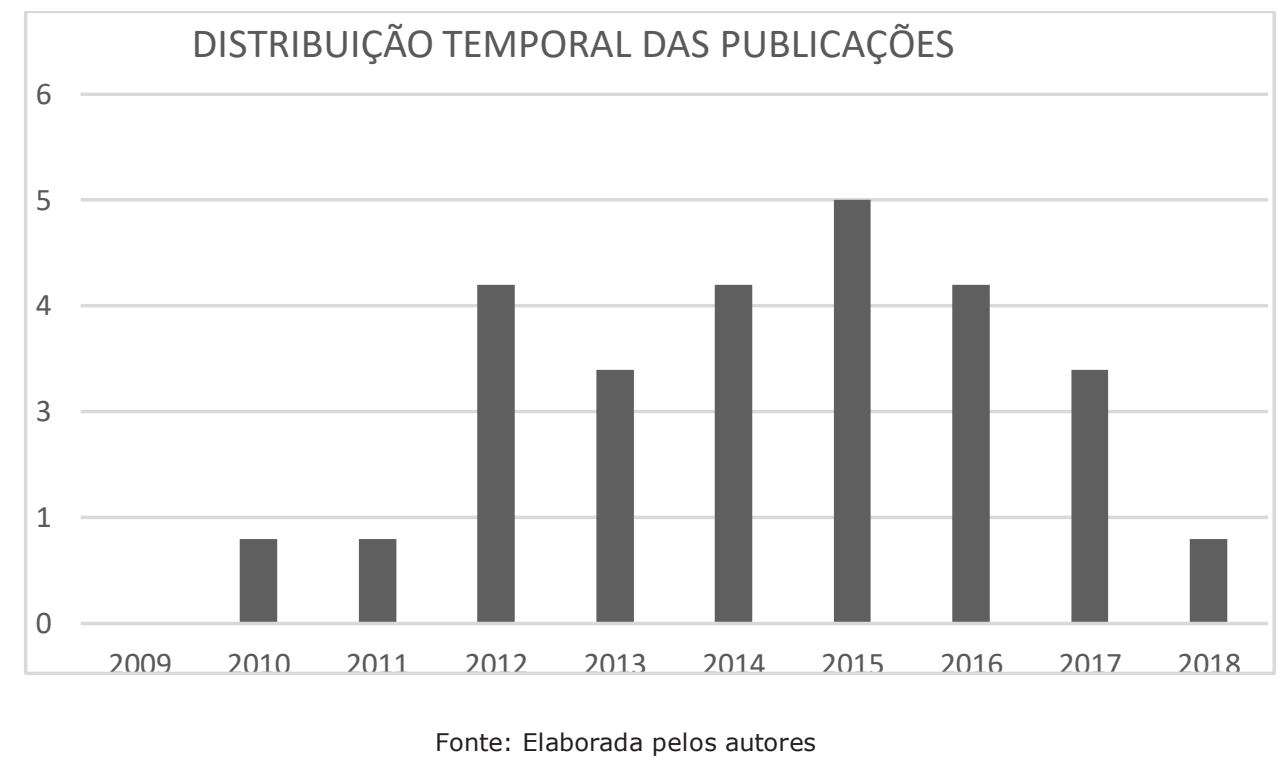

Embora os trabalhos retornados compreendam diferentes períodos, as publicações consideradas como trabalhos primários abrangem os anos de 2010 a 2018, havendo uma zona de silêncio em 2009. Contudo, é possível identificar um número expressivo de publicações entre os anos de 2012 e 2017, com a quantidade de produções em destaque para o ano de 2015.

No que concerne às regiões e/ou países nos quais foram desenvolvidas as pesquisas consideradas como trabalhos primários, verificamos que, de acordo com a Figura 4 (quatro), os Estados Unidos têm liderado as produções de pesquisa sobre a referida temática, com um total de 9 (nove) publicações, representando 34,6\% seguido do Japão com 5 (cinco) publicações, representando 19,2\%, Brasil e Reino Unido com 2 (duas) publicações, representando 7,7\% , Romênia, Taiwan, Alemanha, Arábia Saudita, Espanha, República Eslovaca e Israel com 1 (uma) publicação, representando 3,8\%, dentro das publicações que desenvolveram estudos relacionados ao uso de robôs humanoides com fins educacionais. 
Figura 4 - Quantitativo de desenvolvimento de pesquisas por regiões

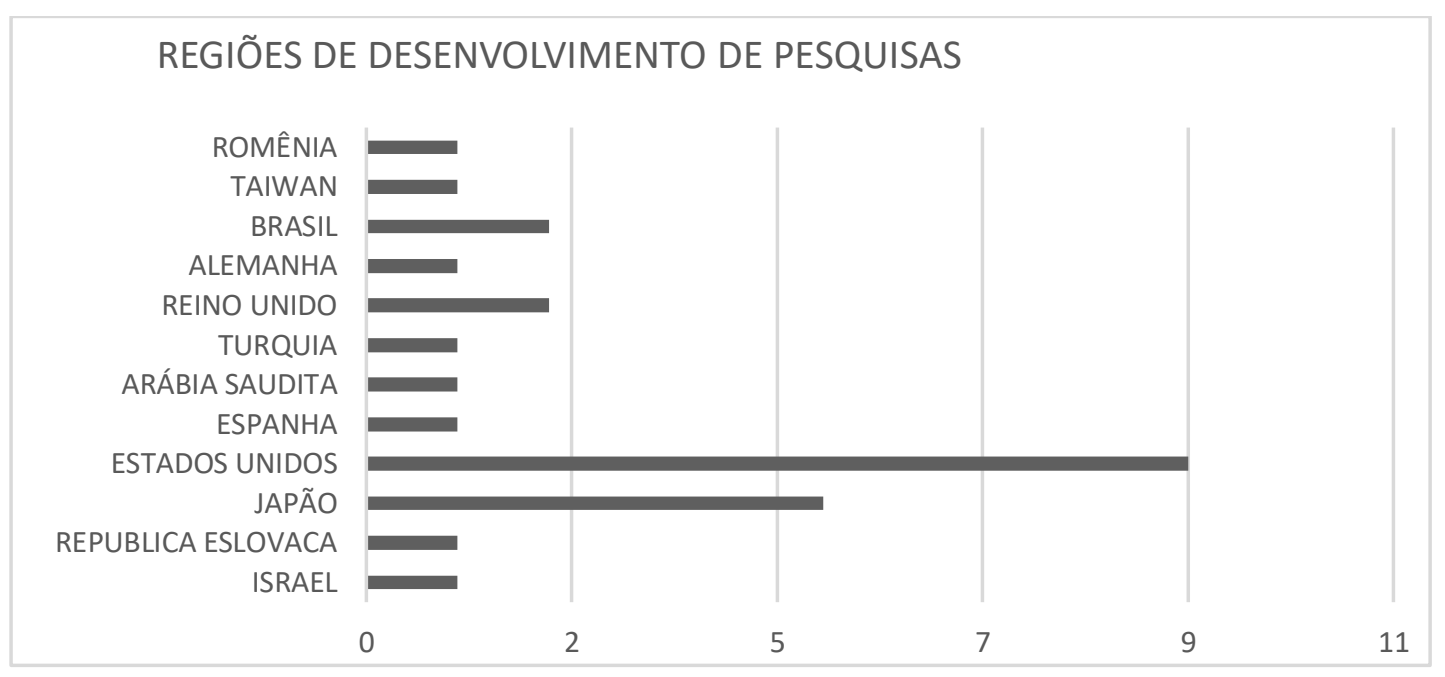

Fonte: Elaborada pelos autores

Após apresentarmos detalhadamente os resultados obtidos no processo de MSL realizado, discorremos a seguir sobre as principais aplicações dos robôs humanoides na educação em seus diferentes níveis e modalidades.

\subsection{Aplicações dos robôs humanoides no contexto educacional}

A análise dos trabalhos primários revela a utilização de robôs humanoides em diferentes níveis e modalidades educacionais no contexto nacional e internacional. Tendo em vista o uso da respectiva tecnologia também em diferentes sistemas de ensino, em busca de uma melhor compreensão, iniciamos nossas reflexões a partir da organização do sistema de ensino brasileiro estabelecido pela Lei de Diretrizes e Bases da Educação (LDB) 9.394/96, apresentado na Figura 5 (cinco): 
Figura 5 - Organização do Sistema de Ensino brasileiro conforme a Lei no 9,394/96(LDB)

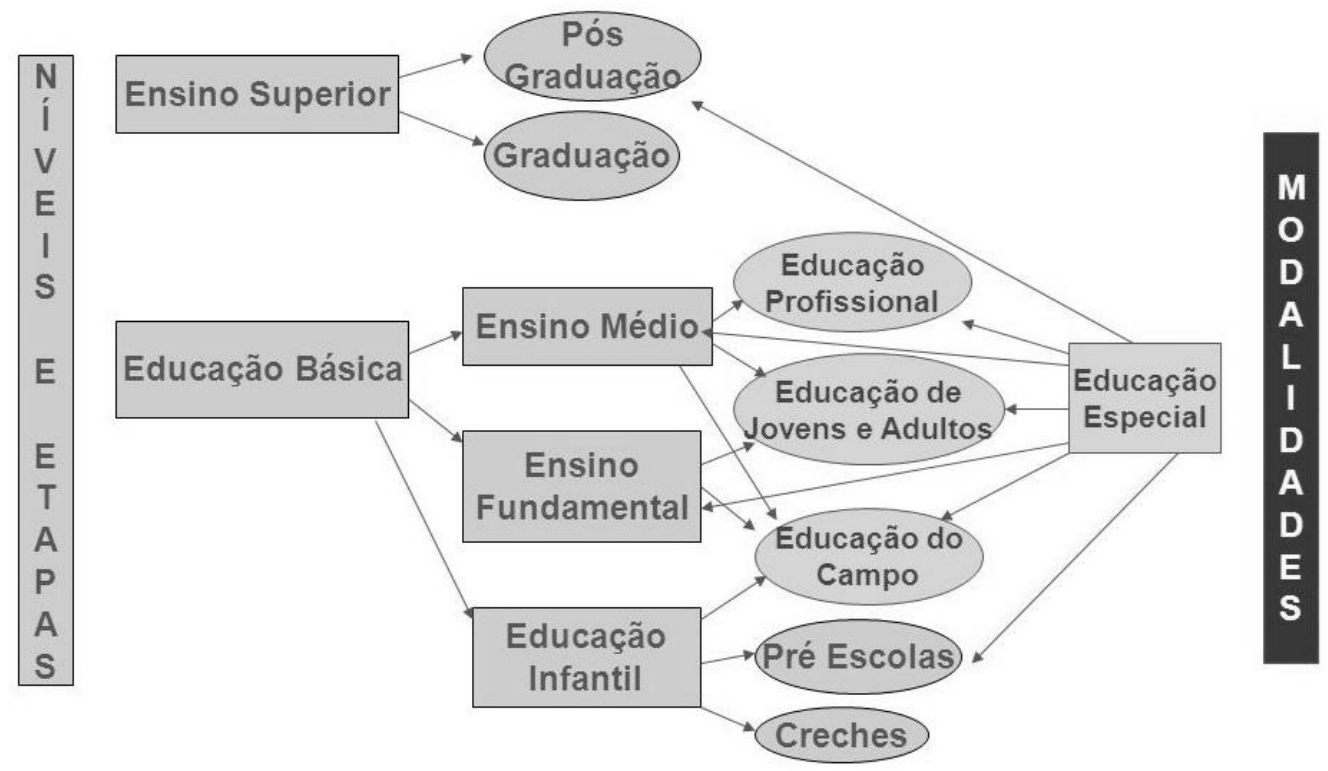

Fonte: Disponível em: http://slideplayer.com.br/slide/293758/ Acesso em: 20/05/2018.

Conforme a Tabela 3 (três), na qual, após leitura individual dos trabalhos, estão apresentados os níveis/modalidades de ensino e respectivas pesquisas.

Tabela 3 - Publicações e modalidades de ensino

\begin{tabular}{|c|c|}
\hline Níveis e Modalidades & Publicações \\
\hline Educação Básica & $\begin{array}{l}\text { (VERNER; POLISHUK; KRAYNER, 2016),(TANAKA } \\
\text { et al., 2015), (BROWN; HOWARD, 2015), } \\
\text { (ALKHALIFAH et al., 2015), (YORITA; BOTZHEIM; } \\
\text { KUBOTA, 2013), (KENNEDY et al., 2016), (PINTO; } \\
\text { TOZADORE; ROMERO, 2016), (EGUCHI; OKADA, } \\
\text { 2018), (SAYLOR et al., 2010), (KAHN et al., 2012), } \\
\text { (LEVCHAK, 2016), (KIM; SMITH, 2017) }\end{array}$ \\
\hline Educação Superior & $\begin{array}{l}\text { (BLAR et al., 2014), (DEDERICHS-KOCH; ZWIERS, } \\
\text { 2015), (LIU; WANG; WANG, 2011), (BACIVAROV; } \\
\text { ILIAN, 2012), (MIRANDA et al., 2012) }\end{array}$ \\
\hline Educação Especial & $\begin{array}{l}\text { (ÖZKUL et al., 2014), (ASLAM et al., 2016), } \\
\text { (WARREN et al., 2015a), (BEKELE et al., 2014), } \\
\text { (CHARRON; LEWIS; CRAIG, 2017), (WARREN et } \\
\text { al., 2015b) }\end{array}$ \\
\hline Não especificado & $\begin{array}{l}\text { (MAGYAR et al., 2014), (NOMURA; KANDA, 2012), } \\
\text { (SUN; LI; NISHIMORI, 2017) }\end{array}$ \\
\hline
\end{tabular}


A maioria dos trabalhos, sendo eles 50\%, demonstra que o uso de robôs humanoides está centrado na educação básica. Em seguida, 22\% dos estudos têm foco na Educação Especial. É importante ressaltar, conforme ilustra a Figura 6 (seis), como se deve entender e ofertar os serviços da educação especial, como parte integrante do sistema educacional brasileiro, em todos os níveis de educação e ensino.

Figura 6 - Educação Especial no Sistema Educacional brasileiro

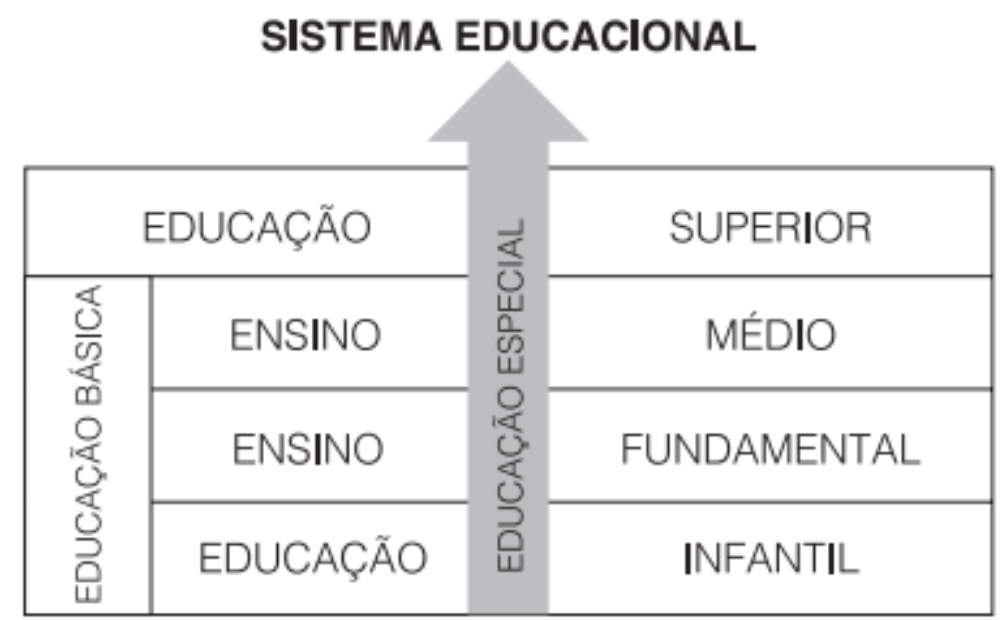

Fonte: (BRASIL, 2001, p. 38)

A Educação Especial é, segundo Carvalho (1994), o processo de desenvolvimento global das potencialidades de pessoas com necessidades educativas especiais, de condutas típicas e de altas habilidades e abrange os diferentes níveis e graus do sistema de ensino.

Com os avanços tecnológicos, recursos informatizados têm sido inseridos nas escolas, com o intuito de proporcionar condições significativas de aprendizagens. Para a educação especial, tais recursos devem ter características específicas, que considerem a individualidade de cada educando, bem como auxiliar as pessoas com necessidades educativas especiais a desenvolver as suas habilidades ou potencial, visando à independência e ao seu máximo funcionamento em todos os sentidos (ARDORE, M.; REGEN, M.; HOFFMANN, 1990).

Há ainda aplicações do uso de robôs humanoides na Educação Superior, compreendendo 18\% dos trabalhos. Outras contribuições do uso de robôs humanoides na educação não especificam nível ou modalidade de ensino, representando $10 \%$ dos trabalhos, a exemplo da pesquisa realizada por Magyar et al. (2014), os quais propõem um estudo das interações e o papel da emoção no processo de aprendizagem mediada por robôs humanoides. Nessa mesma perspectiva, Nomura e Kanda (2012) buscam avaliar aspectos psicológicos, tais como medo, receio do futuro, entre outros. Os autores Sun, Li e Nishimori (2017) analisam o uso de robôs humanoides como assistente de ensino e apoio a professores. 
Ao propormos uma discussão com olhar ao currículo, delineamos as reflexões a seguir com base nos Parâmetros Curriculares Nacionais (PCN):

\begin{abstract}
A denominada "revolução informática" promove mudanças radicais na área do conhecimento, que passa a ocupar um lugar central nos processos de desenvolvimento, em geral. É possível afirmar que, nas próximas décadas, a educação vá se transformar mais rapidamente do que em muitas outras, em função de uma nova compreensão teórica sobre o papel da escola, estimulada pela incorporação das novas tecnologias (BRASIL, 2000a, p. 5).
\end{abstract}

Nesse contexto e com base na discussão dos trabalhos, organizamos a análise em 4 (quatro) categorias, as quais denominamos áreas temáticas, a saber: Linguagem, Códigos e suas Tecnologias (BRASIL, 2000b), Ciências da Natureza, Matemáticas e suas Tecnologias (BRASIL, 2000c), Ciências Humanas e suas Tecnologias (BRASIL, 2000d) e Competências e habilidades sociais, culturais, afetivas e psicomotoras, esta última criada à luz dos dados e alinhada às Diretrizes Curriculares Nacionais.

\title{
4.2.1 Linguagem, Códigos e suas Tecnologias
}

No que se refere ao desenvolvimento de Competência e Habilidades relacionadas aos conhecimentos em Linguagem, destacamos os trabalhos realizados por Tanaka et al. (2015), no qual os autores fazem uso educacional do robô Pepper, em um cenário educativo voltado para o ensino e aprendizagem da língua inglesa, como língua materna. Ainda no contexto da aprendizagem de idiomas assistidas por robôs utilizando o método baseado na teoria cognitiva social, os pesquisadores Yorita, Botzheim e Kubota (2013) explicam o conceito de auto-eficácia para avaliar a condição de aprendizagem mediada por robôs. Os resultados experimentais mostraram a eficácia da proposta do método de comunicação ao longo da interação entre humano e robô.

Kim e Smith (2017) propõem seis estratégias pedagógicas baseadas em teorias que norteiam a interação de aplicativos móveis para crianças. Com vistas a amplificar as contribuições advindas dos dispositivos móveis, foi utilizado um robô humanoide integrado a um smartphone e desenvolvido um aplicativo para aprendizado da língua inglesa, como língua materna. As observações dos autores no uso individual das crianças apoiam uma premissa promissora quanto às estratégias de ensino, combinando robôs e dispositivos móveis como uma opção viável para ajudar a otimizar o aprendizado.

A autora Levchak (2016) realizou um estudo com dois objetivos distintos. Em um primeiro momento, procurou investigar o uso de um robô humanoide como ferramenta eficaz para envolver e aumentar o engajamento de estudantes em um programa de alfabetização. Em segundo, verificou de que maneira a interação homem-máquina afeta a compreensão de leitura dos alunos quando em comparação com as formas tradicionais de ensino. Os sujeitos do estudo foram estudantes economicamente desfavorecidos de grupos sub representados em uma escola secundária com programa de alfabetização. O desenho da pesquisa foi um estudo de caso experimental, com abordagem de métodos mistos. Em um primeiro momento, métodos quantitativos foram usados para coletar informações conhecidas (níveis de compreensão e 
engajamento), em um segundo momento, utilizou métodos qualitativos, os quais permitiram explicações sobre o porquê e como os fenômenos em práticas de letramento ocorrem. No período em que o estudo foi desenvolvido, existia um corpo limitado de pesquisas relacionadas ao uso de robôs humanoides e engajamento. Como resultado, verificaram-se contribuições significativas no uso de robôs humanoides em atividades de alfabetização, com aumento do engajamento dos estudantes no processo de aprendizagem.

Com base no uso de jogos robóticos interativos, Özkul et al. (2014) analisaram a utilização de robôs humanoides na educação e terapia de crianças, dentro de um projeto baseado em jogos de interação homem-robô e computador-humano, com gestos não-verbais e imitação, com o propósito de ensinar a linguagem de sinais para surdos e ouvintes. O robô humanoide atua como um parceiro social e assistente nos jogos para motivar a criança, ensinar sinais não verbais, avaliar o esforço e dar feedback apropriado para melhorar o nível de aprendizagem. Nos jogos, vídeos do robô são utilizados e o desempenho das crianças com deficiência auditiva é avaliado em termos de critérios de avaliação subjetiva e objetiva. Verifica-se, neste estudo, a importância de jogos assistidos por robôs humanoides para uma aprendizagem efetiva da linguagem de sinais.

No âmbito da aprendizagem de conhecimentos de informática, Eguchi e Okada (2018) relatam uma experiência através de uma competição de robótica com robôs sociais utilizados por alunos do ensino fundamental e médio, os quais desenvolveram soluções de programações para resolução de problemas, utilizando robôs sociais. Havia 13 (treze) equipes de vários países que participaram no seminário de dois dias e meio com vistas a aprender programar o robô Pepper e dois dias de competição, em que eles demonstraram seu trabalho. Durante o julgamento de dois dias, embora houvesse algumas falhas, todas as equipes demonstraram suas soluções e desempenho.

Um curso introdutório para realização de movimento de robô humanoide para estudantes de graduação e pós-graduação foi apresentado em um estudo proposto por Liu, Wang e Wang (2011). As operações básicas do acionamento de motores e a combinação da estrutura mecânica de um robô humanoide foram realizadas com base nos principais conceitos de sistemas multilink, Ponto de Momento Zero (ZMP) e controle de realimentação que foram então introduzidos de forma que os alunos possam entender a relação entre a posição do ZMP e a estabilidade do robô. Na pesquisa, os alunos puderam avaliar a trajetória de movimento desejada realizada pelo robô humanoide. Através dessa experiência, foi possível não apenas aprender teorias robóticas e técnicas de controle para movimentos de robôs humanoides, mas também aprimorar vivências em experimentos práticos para executar o movimento de um robô humanoide. Os autores constataram que a estratégia educacional proposta pode vir a permitir que os alunos partícipes da pesquisa venham progredir facilmente em trabalhos mais avançados sobre design e controle de robôs humanoides em seus futuros estudos ou carreiras.

Miranda et al. (2012) apresentam uma metodologia construtivista orientada para a formação em robótica em sentido amplo, através da implementação de uma oficina desenvolvida com alunos do curso de Engenharia Industrial. A referida oficina cobriu um terço das práticas de 
laboratório. Uma visão construtivista para a aprendizagem foi adotada, por meio da qual tecnologias não foram vistas como meras ferramentas, porém, como veículos de novas maneiras para pensar sobre ensino, aprendizagem e educação em geral. Alunos em um ambiente com proposta de aprendizagem construtivista são convidados a trabalhar em experimentos e resolução de problemas, com uso seletivo de recursos disponíveis de acordo com seus próprios interesses, estratégias de pesquisa e aprendizagem. Os autores, como formadores dessa oficina, selecionaram materiais e peças para constituição do robô, sensores e software de programação com uma interface gráfica simples destinada à criação de movimentos comportamentais do robô humanoide. Nessa perspectiva, as oficinas realizadas corroboraram com uma abordagem de aprendizagem significativa baseada em projetos em robótica.

De acordo com o MSL realizado, não foram identificados trabalhos que explorassem 0 desenvolvimento de conhecimento em Educação Física e Arte.

\subsubsection{Ciências da Natureza, Matemáticas e suas tecnologias}

No âmbito das Ciências da Natureza, Matemática e suas Tecnologias, destacamos os trabalhos de Verner, Polishuk e Krayner (2016), ao realizar um estudo cujo foco principal foi a análise do aprendizado individual com robôs, avaliando a eficácia em aprender novos conceitos de ciências, em que os resultados mostraram que os objetivos educacionais foram alcançados.

O estudo da classificação de seres vivos e não vivos também é experimentado por Saylor et al. (2010), no estudo de caso, pediu-se a crianças de três e quatro anos que atribuíssem uma variedade de propriedades associadas a coisas vivas e máquinas a artefatos complexos desafiadores de categoria (robôs humanoides), uma coisa viva familiar (uma garota) e um artefato complexo familiar (uma câmera). Os resultados demonstraram que crianças de quatro anos de idade tendem a tratar entidades que desafiam a categoria, como membros do grupo inanimado, enquanto crianças de três anos mostram mais variabilidade em suas respostas. Esse achado sugere que a capacidade dos pré-escolares de classificar artefatos complexos que cruzam a divisão não viva torna-se mais estável entre as idades de três e quatro anos e que crianças de ambas as idades baseiam-se em uma variedade de propriedades ao classificar tais entidades.

Para aprendizagem de partes do corpo humano, reconhecimento de animais, entre outros, Alkhalifah et al. (2015) propõem um sistema que facilita o processo educacional de crianças, utilizando robô humanoide programado para apoiar a aprendizagem de forma lúdica, através do fornecimento de muitas atividades e jogos. O estudo do uso do robô humanoide forneceu possibilidades para verificar uma compreensão satisfatória dos alunos envolvidos.

Kennedy et al. (2016) apresentam um estudo no qual a aprendizagem e os ganhos das crianças são comparados quando se ensina a matemática tradicional por um tutor robô e um ser humano não especialista tutor. A aprendizagem significativa ocorre em ambas as condições, mas as crianças melhoram mais com o tutor humano. Essa diferença não é estatisticamente significativa, entretanto, mostraram que os humanos superam tecnologia para tutoria e/ou ensino. 
Ainda sobre a utilização para aprendizagem de conceitos matemáticos, Pinto, Tozadore e Romero (2016) e Pinto (2014) utilizam um jogo de perguntas para verificar a aprendizagem de crianças em relação à classificação de figuras geométricas. Dois grupos de crianças de 11 a 14 anos foram comparados depois de terem aulas com o robô, cada grupo com um nível diferente de interações, participando do jogo. Os resultados obtidos revelam que o desempenho das crianças com alta interação como o robô foi melhor em comparação com o grupo de baixa interação. Isso sugere que um robô de alta interação pode vir a auxiliar os professores, além de contribuir para o desenvolvimento de aspectos motivacionais.

No ensino de Engenharia Mecânica, a cinemática de corpos rígidos representa um tópico típico que apresenta o desafio de inspirar os alunos a conteúdos bastante teóricos, que, muitas vezes, são percebidos como sendo de pouco benefício na resolução de problemas práticos. Nesse contexto, com o objetivo de destacar a relevância prática de conceitos aparentemente abstratos e, assim, aumentar a motivação do aluno, Dederichs-Koch e Zwiers (2015) analisam uma unidade de aprendizagem interativa com base no uso de robôs humanoides, de modo que através da cinemática inversa, a distância do robô em direção a um objeto é calculada. Para verificar os resultados analíticos, os alunos são incentivados a programar o robô em um ambiente de aprendizado baseado em projetos. A implementação de tal unidade de aprendizagem baseada em projetos é delineada, incluindo uma discussão sobre o conhecimento prévio necessário dos alunos participantes e uma descrição detalhada da parte analítica e experimental do projeto.

As pesquisas de um modo geral revelam a possibilidade didática do uso de robôs humanoides nas Ciências da Natureza, Matemática e suas Tecnologias ao permitir a exploração de diferentes conceitos em múltiplos contextos.

De acordo com o MSL, não foram identificados trabalhos que explorassem o desenvolvimento de competências e habilidades na área de Química.

\subsubsection{Ciências Humanas e suas Tecnologias}

As Ciências Humanas e suas Tecnologias estão estabelecidas nos PCN (BRASIL, 2000d), abrangendo conhecimentos de História, Geografia, Sociologia, Antropologia, Política e Filosofia. Apesar da relevância da referida área, seja pelo senso de responsabilidade perante o social pelo qual se exige conhecimentos de História, Sociologia, Política, entre outros, que deem conta de diferentes questões que emergem da contemporaneidade, ou pelo fato de se constituir por sua própria natureza do ponto de vista epistemológico, um campo privilegiado para discussão de diferentes questões, após a análise individual dos trabalhos primários, não foram encontrados estudos que abordassem a área.

\subsubsection{Competências e habilidades sociais, culturais, afetivas e psicomotoras}

Cada vez mais pesquisadores estão tentando desenvolver tecnologias robóticas para crianças com Transtorno do Espectro do Autista (TEA). Neste sentido, através do mapeamento sistemático realizado, verificamos estudos relevantes relacionados ao uso de robôs humanoides em práticas 
terapêuticas de crianças com TEA. Warren et al. (2015a) investigaram o desenvolvimento e a aplicação de um novo sistema robótico capaz de interação dinâmica, adaptativa e autônoma durante tarefas de imitação com avaliação e feedback de desempenho dos sujeitos envolvidos em tempo real. O sistema foi projetado para incorporar um robô humanoide e um examinador humano. O desempenho infantil foi comparado dentro do sistema nessas condições em uma amostra de crianças pré-escolares com TEA $(n=8)$ (onde $n$ corresponde ao número de participantes da pesquisa) e uma amostra controle de desenvolvimento típico, revelando avanços das crianças em processos de interação com o robô humanoide. Warren et al. (2015b) também publicaram um segundo trabalho, ao analisar a aplicação de um novo sistema de interação robótico capaz de controlar um aplicativo de atenção conjunta a um grupo de crianças $(n=6)$ de crianças com TEA. Em uma série de quatro sessões, observaram como as crianças melhoraram sua capacidade de orientar os prompts administrados pelo sistema robótico e continuaram a mostrar uma forte atenção para o robô humanoide ao longo do tempo. Os potenciais dos recursos robóticos para as estratégias de ação dirigida, bem como a importância do uso das plataformas robóticas humanas são evidenciadas na pesquisa.

Na busca por descrever uma possível metodologia para o desenvolvimento de habilidades de atenção conjunta em estudantes com TEA, a terapia co-robótica com o robô humanoide NAO foi usada para promover o desenvolvimento de habilidades de atenção conjunta dos sujeitos investigados. Sessões de 20 min realizadas uma vez por semana durante o ano letivo foram gravadas em vídeo e analisadas para atenção conjunta. Para Charron, Lewis e Craig (2017), a terapia com robôs pode ser um método viável para melhorar as habilidades de comunicação em indivíduos identificados com o TEA, sendo que, no estudo realizado pelos pesquisadores, o sujeito da pesquisa em particular mostrou-se motivado por trabalhar com um robô humanoide.

Com base nas pesquisas anteriores, é sabido que robôs humanoides podem vir a contribuir nos processos de construção do conhecimento, bem como melhorar os processos de interação e comunicação em crianças público-alvo da Educação Especial, em específico com TEA. No entanto, a maioria das escolas que visam à reabilitação ou continuidade ao Atendimento Educacional Especializado (AEE) não pode comprar um robô humanoide devido aos altos custos. Poderia um robô Lego Mindstorm, não humanoide e mais barato, ser uma forma alternativa de atingir os mesmos objetivos de aprendizagem que o robô humanoide?

Para responder essa questão, Aslam et al. (2016) delinearam um estudo de caso único, de natureza experimental, com 16 sessões ao longo de cinco semanas: 8 (oito) com robô humanoide e 8 (oito) com o robô não humanoide. Todas as sessões foram gravadas em vídeo e analisadas quanto ao percentual de engajamento e erros percentuais feitos por cada um dos quatro alunos com déficit intelectual. Para cada aluno individualmente, essas medidas de desfecho foram então comparadas entre as duas condições. Os professores foram entrevistados no final do estudo. Três de quatro alunos estavam significativamente mais envolvidos com o robô não humanoide do que com o robô humanoide, enquanto um estudante foi considerado igualmente envolvido com os dois robôs. Não houve diferença significativa entre os dois robôs em termos de erros percentuais para todos os quatro participantes que conseguiram concluir o estudo. 
Para Kahn et al. (2012), as crianças crescem cada vez mais com os robôs personificados, formam relações sociais e até morais com eles. Como serão essas relações? Para resolver essa questão, 90 crianças (nove, 12 e 15 anos de idade), inicialmente, interagiram com um robô humanoide, o Robovie, em sessões de 15 min. Cada sessão terminava quando um experimentador interrompia a vez de Robovie em um jogo e, contra as objeções de Robovie, colocava Robovie em um armário. Cada criança foi envolvida em uma entrevista de desenvolvimento estrutural de 50 minutos. Os resultados mostraram que, durante as sessões de interação, todas as crianças envolveram-se em comportamentos sociais físicos e verbais com Robovie. Os dados da entrevista mostraram que a maioria das crianças acreditava que Robovie tinha estados mentais (por exemplo, era inteligente e tinha sentimentos) e era um ser social (por exemplo, poderia ser um amigo, oferecer conforto e ser confiável com segredos). Em termos da posição moral de Robovie, as crianças acreditavam que Robovie merecia tratamento justo e não deveria ser prejudicado psicologicamente, mas não acreditavam que Robovie tinha direito à sua própria liberdade (Robovie poderia ser comprado e vendido) ou direitos civis (em termos de direitos de voto e merecer compensação pelo trabalho realizado). Em termos de desenvolvimento, enquanto mais da metade dos jovens de 15 anos conceituou Robovie como um outro ser mental, social e parcialmente moral, eles o fizeram em um grau menor do que os de nove e 12 anos. A discussão focou sobre como as relações sociais e morais das crianças com futuros robôs personificados podem ser substanciais e significativas e de que maneira os robôs personificados do futuro podem emergir como uma categoria ontológica única.

Sob a égide das emoções, Magyar et al. (2014) propõem uma pesquisa na qual o componente emoções sintéticas estão sendo investigada em processos de interação, incluindo o modelo de emoções de Plutchik baseado em fuzzy. No estudo, as emoções devem aumentar com base na eficácia dos procedimentos de ensino, como também na realização de uma avaliação lógica. 0 banco de dados baseado em nuvem conteve várias abordagens educacionais desenvolvidas para o robô humanoides, verificando a importância das emoções na interação homem-máquina.

\section{Considerações Finais}

A presente pesquisa procurou junto a um objetivo maior investigar como se dá o uso de robôs humanoides na educação no âmbito nacional e internacional, refletindo sobre os aspectos metodológicos, didáticos e curriculares, presentes nas práticas educativas pautadas na aplicação de artefatos tecnológicos. As etapas do MSL apresentadas permitiram encontrar 26 (vinte e seis) trabalhos primários, entendidos como artigos científicos originais, publicados em conferências e revistas relevantes na área. Essa quantidade denota a relevância dessa subárea, apesar de ser um campo de estudo recente no contexto educacional, e ainda pouco estudado no Brasil.

Os resultados deste MSL evidenciam-se na diversidade de tipos de robôs humanoides utilizados nas pesquisas, bem como a utilização deles em todos os níveis/modalidades de ensino, com maior frequência na Educação Básica. Outro ponto a ser destacado está relacionado ao uso de robôs humanoides na Educação Especial, o que se mostrou significativo em processos e 
práticas educacionais de crianças com TEA, contribuindo para o exercício de ações sociais, culturais, afetivas e psicomotoras.

Ao refletirmos sobre as diferentes áreas temáticas analisadas, é possível identificar diversas lacunas quanto a pesquisas que explorassem o desenvolvimento de conhecimento em Educação Física, Arte, Química, História, Geografia, Sociologia, Antropologia, Política e Filosofia.

Diante de tal consideração, compreendemos, com base na presente investigação, o importante papel dos robôs humanoides, em áreas temáticas tais como Linguagem, Códigos e suas Tecnologias e Ciências da Natureza, Matemática e suas Tecnologias, apesar da existência de uma lacuna nas Ciências Humanas e suas Tecnologias, esses artefatos, aliados a uma metodologia adequada, podem vir a mobilizar o potencial de aprendizagem, bem como contribuir para o desenvolvimento de competências e habilidades em diversas áreas do conhecimento.

Evidenciamos ainda, quanto aos componentes curriculares, que o uso de robôs humanoides está concentrado no ensino de Línguas, Informática, Física e Matemática, revelando um campo fértil para investigações relacionadas ao desenvolvimento da linguagem, pensamento computacional, compreensão de conceitos nas áreas de Física e Matemática, para além de uma abordagem puramente teórica, mas com viés prático, crítico-reflexivo e criativo.

Assim, ao registrarmos as conclusões obtidas pelo presente Mapeamento Sistemático da Literatura, sugerimos o desenvolvimento de novas pesquisas que versem sobre essa temática.

Neste sentido, indicamos algumas, como desdobramentos de nossos estudos. Uma problemática a ser discutida trata da formação inicial e/ou continuada de professores para o uso de robôs humanoides, com vistas a refletir sobre os aspectos didáticos e metodológicos do seu uso no ambiente escolar.

A questão das políticas e práticas curriculares é um tema ainda pouco explorado e, com isso, requer investigações. No presente mapeamento sistemático, identificamos que não existe uma proposta de inserção curricular dessa ferramenta, então, será que sua real implantação existe? Ou o uso de robôs humanoides está inserido em um modismo pedagógico?

Outro campo fértil de estudos é as contribuições dos robôs humanoides aplicadas ao ensino de crianças público-alvo da Educação Especial. Um exemplo é a utilização de robôs em práticas de ensino de crianças autistas, ou até mesmo com TDAH (Transtorno de Déficit de Atenção e Hiperatividade). Conchinha (2011) realizou uma pesquisa em Portugal com crianças com paralisia cerebral e revelou que a Robótica Educacional pode ser utilizada no contexto educativo como parte de uma terapia de reabilitação motora, o que, neste sentido, é possível investigar as contribuições viáveis desse recurso para o desenvolvimento de competências e habilidades.

Por fim, oriundos dessa temática, além das sugestões elencadas, outros estudos podem emergir, tendo em vista que o campo de pesquisa sobre o uso de robôs humanoides é um paradigma recente e, nesse panorama, requer novas pesquisas e análise de aplicações desenvolvidas no cenário educacional, em diferentes contextos. 


\section{Agradecimentos}

O presente trabalho foi realizado com apoio da Coordenação de Aperfeiçoamento de Pessoal de Nível Superior (CAPES) e apoio da Universidade Federal de Mato Grosso do Sul (UFMS).

\section{Referências}

ARDORE, M.; REGEN, M.; HOFFMANN, V. M. B. Eu tenho um irmão deficiente... vamos conversar sobre isso? SÃO PAULO: Paulinas, 1990.

ASLAM, S. et al. A comparison of humanoid and non humanoid robots in supporting the learning of pupils with severe intellectual disabilities. Proceedings - 2016 International Conference on Interactive Technologies and Games: EduRob in Conjunction with iTAG 2016, iTAG 2016, n. Id, p. 7-12, 2016.

BACIVAROV, I. C.; ILIAN, V. L. M. The paradigm of utilizing robots in the teaching process: A comparative study. International Journal of Technology and Design Education, v. 22, n. 4, p. 531-540, 2012.

BEKELE, E. et al. Pilot clinical application of an adaptive robotic system for young children with autism. Autism, v. 18, n. 5, p. 598-608, 2014.

BEKEY, G. et al. Space Robotics. In: Robotics: State Of The Art And Future Challenges. Imperial College Press, 2008.

BLAR, N. et al. Work in progress: Experimental design on initial investigation of Malaysian technical education using humanoid robot teacher and human teacher. 2014 11th International Conference on Ubiquitous Robots and Ambient Intelligence, URAI 2014, n. Urai, p. 504-505, 2014.

BRASIL, M. D. E. PARÂMETROS CURRICULARES NACIONAIS PARA O ENSINO MÉDIO: BASES LEGAIS. BRASILIA: MEC/SEF, 2000a.

BRASIL, M. D. E. PARÂMETROS CURRICULARES NACIONAIS ENSINO MÉDIO: LINGUAGENS, CÓDIGOS E SUAS TECNOLOGIAS. BRASI: MEC/SEF, 2000b.

BRASIL, M. D. E. PARÂMETROS CURRICULARES NACIONAIS ENSINO MÉDIO: CIÊNCIAS DA NATUREZA E SUAS TECNOLOGIAS. BRASILIA: MEC/SEF, 2000c.

BRASIL, M. D. E. PARÂMETROS CURRICULARES NACIONAIS ENSINO MÉDIO: CIÊCIAS HUMANAS E SUAS TECNOLOGIAS. BRASILIA: MEC/SEF, 2000d.

BRASIL, M. D. E. Diretrizes Nacionais para a Educação Especial na Educação Básica. SÃo PAULO: SECRETARIA DE EDUCAÇÃO ESPECAL-SEESP, 2001.

BROWN, L.; HOWARD, A. M. Engaging children in math education using a socially interactive humanoid robot. IEEE-RAS International Conference on Humanoid Robots, v. 2015-Febru, n. February, p. 183-188, 2015.

CARVALHO, R. E. A política da educação especial no Brasil. In: Tendências e desafios da educação especial. Brasília: Secretaria de Educação Especial, 1994.

CHARRON, N.; LEWIS, L.; CRAIG, M. A Robotic Therapy Case Study. Journal of Educational Technology Systems, v. 46, n. 1, p. 137-148, 2017.

CONCHINHA, C. Lego Mindstorms: Um estudo com utentes com paralisia cerebral. Disponível em: <http://repositorio.ul.pt/bitstrem/10451/5747/1/ulfpie039843_tm.pdf>. Acesso em: 22 maio. 2018. 
DEDERICHS-KOCH, A.; ZWIERS, U. Project-based Learning Unit: Kinematics and Object Grasping in Humanoid Robotics. 2015.

EGUCHI, A.; OKADA, H. Learning with Social Robots - The World Robot Summit's Approach. v. 00, n. c, p. 53-56, 2018.

KAHN, P. H. et al. "Robovie, you'll have to go into the closet now": Children's social and moral relationships with a humanoid robot. Developmental Psychology, v. 48, n. 2, p. 303-314, 2012.

KENNEDY, J. et al. Heart vs hard drive: Children learn more from a human tutor than a social robot. ACM/IEEE International Conference on Human-Robot Interaction, v. 2016-April, p. 451-452, 2016.

KIM, Y.; SMITH, D. Pedagogical and technological augmentation of mobile learning for young children interactive learning environments. Interactive Learning Environments, v. 25, n. 1, p. 4-16, 2017.

LEVCHAK, S. Robotic Literacy Learnin Companios Exploring Student Egagement With A Humanoid robot In: An Afterschool Literacy program.

LIU, H. Y.; WANG, W. J.; WANG, R. J. A course in simulation and demonstration of humanoid robot motion. IEEE Transactions on Education, v. 54, n. 2, p. 255-262, 2011.

MAGYAR, G. et al. Towards adaptive cloud-based platform for robotic assistants in education. SAMI 2014 IEEE 12th International Symposium on Applied Machine Intelligence and Informatics, Proceedings, p. 285289, 2014.

MIRANDA, A. et al. Work in progress: A constructivist didactic methodology for a humanoid robotics workshop. Proceedings - Frontiers in Education Conference, FIE, p. 1-3, 2012.

NOMURA, T.; KANDA, T. Influences of evaluative contexts in human-robot interaction and relationships with personal traits. Proceedings - IEEE International Workshop on Robot and Human Interactive Communication, p. 61-66, 2012.

OLIVEIRA, E. S. ROBÓTICA EDUCACIONAL E RACIOCINIO PROPORCIONAL: UMA DISCUSSÃO À LUZ DA TEORIA DA RELAÇÃO COM O SABER. Universidade Estadual da Paraíba-UEPB, 2015.

ÖZKUL, A. et al. Robostar: An interaction game with humanoid robots for learning sign language. 2014 IEEE International Conference on Robotics and Biomimetics, IEEE ROBIO 2014, p. 522-527, 2014.

PINTO, A. H. M. Um sistema de reconhecimento de objetos incorporado a um robô humanoide com aplicação na educação.

PINTO, A. H. M.; TOZADORE, D. C.; ROMERO, R. A. F. A Question Game for Children Aiming the Geometrical Figures Learning by Using a Humanoid Robot. Proceedings - 12th LARS Latin American Robotics Symposium and 3rd SBR Brazilian Robotics Symposium, LARS-SBR 2015 - Part of the Robotics Conferences 2015, p. 228-233, 2016.

REGIS, F. Nós, ciborgues: tecnologias da informação e subjetividade homem-máquina. Curitiba: Champagnat, 2012.

SAYLOR, M. M. et al. How do young children deal with hybrids of living and non-living things: The case of humanoid robots. British Journal of Developmental Psychology, v. 28, n. 4, p. 835-851, 2010.

SUN, Z.; LI, Z.; NISHIMORI, T. Development and Assessment of Robot Teaching Assistant in Facilitating Learning. p. 165-169, 2017. 
TANAKA, F. et al. Pepper learns together with children: Development of an educational application. IEEERAS International Conference on Humanoid Robots, v. 2015-Decem, p. 270-275, 2015.

VERNER, I. M.; POLISHUK, A.; KRAYNER, N. Science Class with RoboThespian: Using a Robot Teacher to Make Science Fun and Engage Students. IEEE Robotics and Automation Magazine, v. 23, n. 2, p. 74-80, 2016.

WARREN, Z. et al. Brief Report: Development of a Robotic Intervention Platform for Young Children with ASD. Journal of Autism and Developmental Disorders, v. 45, n. 12, p. 3870-3876, 2015a.

WARREN, Z. E. et al. Can Robotic Interaction Improve Joint Attention Skills? Journal of Autism and Developmental Disorders, v. 45, n. 11, p. 3726-3734, 2015b.

YORITA, A.; BOTZHEIM, J.; KUBOTA, N. Self-efficacy using fuzzy control for long-term communication in robot-assisted language learning. IEEE International Conference on Intelligent Robots and Systems, $\mathrm{p}$. 5708-5715, 2013.

Recebido em fevereiro de 20120.

Aprovado para publicação em janeiro de 2021.

\section{Edvanilson Santos de Oliveira}

Programa de Pós-Graduação em Educação Matemática - Universidade Federal do Mato Grosso do Sul - UFMS, Brasil, edvanilsom@gmail.com

\section{Patrícia Sândalo Pereira}

Programa de Pós-Graduação em Educação Matemática - Universidade Federal do Mato Grosso do Sul - UFMS, Brasil, sandalo.patricia13@gmail.com 